\title{
GUARDA COMPARTILHADA: ALGUNS ARGUMENTOS E CONTEÚDOS DA JURISPRUDÊNCIA
}

\author{
Leila Maria Torraca de Brito e Emmanuela Neves Gonsalves
}

\section{RESUMO}

O ARTIGO VISA APRESENTAR RESULTADOS DE PESQUISA A QUAL TEVE COMO OBJETIVO ESTUdAR A MANEIRA COMO A JURISPRUDÊNCIA, EMITIDA POR ALGUNS TRIBUNAIS BRASILEIROS, VEM CONSIDERANDO A POSSIBILIDADE DE APLICAÇÃO DA GUARDA COMPARTILHADA DE CRIANÇAS E DE ADOLESCENTES. NA INVESTIGAÇÃO FORAM ANALISADOS ACÓRDÃOS PROLATADOS POR TRÊS ESTAdOS DA FEDERAÇÃo NO PERÍOdO ENTRE 12 DE AGOSTO DE 2008 - QUANDO ENTROU EM VIGOR A LEI FEDERAL Nº 11698/08, QUE REGULAMENTA A APLICAÇÃO DA GUARDA COMPARTILHADA - E ABRIL DE 2010. AS ARGUMENTAÇÕES QUE ENVOLVIAM CONSIDERAÇÕES SOBRE O BEM-ESTAR PSÍQUICO DE CRIANÇAS E DE ADOLESCENTES FORAM SEPARADAS EM CATEGORIAS E EXAMINADAS À LUZ DOS CONHECIMENTOS DAS CIÊNCIAS HUMANAS. OBSERVOU-SE QUE A NATUREZA DOS ARGUMENTOS UTILIZADOS EM DECISÕES QUE NEGAM A APLICAÇÃO DA GUARDA COMPARTILHADA DIVERGE DO ENTENDIMENTO DE ESTUDOS RECENTES DAQUELA ÁREA DE CONHECIMENTOS.

\section{PALAVRAS-CHAVE}

GUARDA COMPARTILHADA; GUARDA DE FILHOS; CONVIVÊNCIA FAMILIAR; ENTENDIMENTO JURISDICIONAL; JURISPRUDÊNCIA.
JOINT CUSTODY: SOME ARGUMENTS AND CONTENT OF COURT DECISIONS

\begin{abstract}
THE ARTICLE PRESENTS RESULTS OF RESEARCH ON WHICH IT AIMED TO STUDY THE CASE LAW, ISSUED BY SOME BRAZILIAN COURTS, IS CONSIDERING THE POSSIBILITY OF APPLYING THE JOINT CUSTODY OF CHILDREN AND ADOLESCENTS. IN THE INVESTIGATION WE HAVE ANALYZED THE JUDGMENTS HANDED DOWN BY THREE BRAZILIAN STATES IN THE PERIOD BETWEEN AUGUST 12, 2008 - ENTERED INTO FORCE WHEN THE FEDERAL LAW No. 11698/08 WHICH REGULATES THE IMPLEMENTATION OF SHARED CUSTODY - AND IN APRIL 2010. THE ARGUMENTS INVOLVING CONSIDERATIONS OF THE PSYCHOLOGICAL WELL-BEING OF CHILDREN AND ADOLESCENTS WERE CATEGORIZED AND EXAMINED IN THE LIGHT OF KNOWLEDGE OF THE HUMANITIES. IT WAS OBSERVED THAT THE NATURE OF THE ARGUMENTS USED IN DECISIONS THAT DENY THE APPLICATION OF JOINT CUSTODY IS DIFFERENT FROM THE UNDERSTANDING OF RECENT STUDIES OF THE HUMANITIES ON THE SUBJECT.
\end{abstract}

\section{KEYWORDS}

JOINT CUSTODY; CUSTODY OF THE CHILD; FAMILY COURTYARD; COURT DECISIONS; UNDERSTANDING COURT.

\section{INTRODUÇÃO}

No Brasil, a Lei n ${ }^{\circ} 11.698$, de 13 de junho de 2008 (Brasil, 2008), alterou a redação dos artigos 1583 e 1584 do Código Civil para instituir e regulamentar a guarda compartilhada. Enquanto na redação anterior do Código Civil Brasileiro (Brasil, 2002) o artigo 1584 tratava somente da guarda unilateral, observando o critério de melhores condições para exercê-la, o novo ordenamento acrescenta a guarda compartilhada 
como opção para pais e mães não conviventes cuidarem de filhos. Cabe ressaltar que a mudança na legislação pátria se deve a diversos fatores, dentre eles as contundentes reivindicações daqueles que não detinham a guarda de suas crianças e as distintas investigações efetuadas a respeito dos desdobramentos do rompimento conjugal para pais e filhos - o que incluía o exame das disposições de guarda.

Atualmente, no que tange ao artigo 1584 do Código Civil, o $\S 1^{\circ}$ estabelece que o juiz, na audiência de conciliação, deverá informar aos pais o significado da guarda compartilhada, bem como os direitos e as responsabilidades de cada um. Essa determinação, possivelmente, vem ao encontro de queixas apresentadas por muitos pais e mães sobre o desconhecimento em relação ao processo de guarda, fato também observado em países diversos. Wallerstein, Lewis e Blakeslee (2002), em pesquisa longitudinal realizada com famílias norte-americanas que passaram pelo divórcio, perceberam que:

... a maioria dos pais recebe pouca orientação, alguns tribunais oferecem palestras educativas a famílias no momento do rompimento, mas a ênfase está em prevenir litígio posterior. Esses cursos são avaliados geralmente de acordo com o índice de redução que causam nos litígios subseqüentes e não em como podem melhorar o cuidado dos filhos pelos pais (Wallerstein, Lewis e Blakeslee, 2002, p. 353).

Não se pode deixar de mencionar que, a partir da nova disposição legal, a guarda compartilhada pode ser aplicada havendo ou não consenso entre os pais. Como dispõe o $\S 2^{\circ}$ do artigo 1584 do Código Civil: "Quando não houver acordo entre a mãe e o pai quanto à guarda do filho, será aplicada, sempre que possível, a guarda compartilhada”.

Nas discussões sobre o assunto se nota que para alguns autores, como Pelajo (2008), a aprovação da lei que regulamenta a guarda compartilhada representa um grande avanço no sentido de desmembrar conjugalidade e parentalidade, destacando a jurista citada que, dessa forma, ambos os pais são responsabilizados pela educação dos filhos. No estudo da temática, porém, também se observa que pesquisas realizadas no Brasil antes da promulgação da Lei n ${ }^{\circ}$ 11.698/08 apontam contrariedades de operadores do direito a respeito da aplicação dessa modalidade de guarda, sobressaindo justificativas relacionadas aos possíveis prejuízos psicológicos que seriam causados ao desenvolvimento infanto-juvenil.

Visando a apresentar a compreensão de alguns tribunais brasileiros sobre o tema em apreço, optou-se por pesquisar a jurisprudência emitida pelo Tribunal de Justiça do Estado do Rio de Janeiro (TJRJ), pelo Tribunal de Justiça do Rio Grande do Sul (TJRS) e pelo Tribunal de Justiça de Minas Gerais (TJMG), objetivando circunscrever argumentos que sustentam tais acórdãos. Como assevera Carvalho (2010, p. 304), ao analisar o processo enunciativo do direito, "a lógica da linguagem persuasiva ou da 
linguagem que prepara a decisão é a lógica da argumentação, isto é, uma lógica da interpretação para decidir ou lógica dialógica orientada para a decisão”.

Diversos autores (Hurstel, 1999; Théry, 1998) compreendem que as decisões judiciais trazem significativas repercussões ao exercício dos papéis parentais, podendo contribuir tanto para favorecer como para fragilizar a convivência familiar. Por esse motivo, no presente artigo se objetiva apresentar e discutir conteúdos relacionados às ciências humanas, especialmente os que envolvem considerações sobre o bem-estar psíquico de crianças e de adolescentes, presentes em acórdãos emitidos por três tribunais de Justiça brasileiros após a promulgação da Lei nº 11.698/08.

\section{i Metodologia}

Na investigação que se realizou, foi empreendida busca de jurisprudências nas páginas eletrônicas do Tribunal de Justiça do Estado do Rio de Janeiro, do Tribunal de Justiça do Estado do Rio Grande do Sul e do Tribunal de Justiça do Estado de Minas Gerais, empregando-se a expressão "guarda compartilhada”. Optou-se por examinar esses três tribunais pois se observou, quando da realização de pesquisa bibliográfica sobre o tema, que esses foram estados representativos no que diz respeito às discussões levadas a termo ao longo da tramitação do projeto de lei (Brasil, 2002) sobre a guarda compartilhada.

Por meio dessa busca foram coletados os julgados com decisões prolatadas no período entre 12 de agosto de 2008 - quando entrou em vigor a Lei Federal n ${ }^{\circ}$ 11.698/08, que regulamenta a aplicação dessa modalidade de guarda - e abril de 2010. Foram localizados 187 acórdãos, sendo 94 os julgados nos quais foi feita menção a essa modalidade de guarda - 29 do TJRJ, 27 do TJRS e 38 do TJMG - e que tiveram, portanto, suas ementas apreciadas de acordo com o referencial da análise de conteúdo (Gomes, 1998). Cabe esclarecer, ainda, que a jurisprudência estudada se refere a ações de modificação e regulamentação de guarda e a solicitações de aplicação da guarda compartilhada e de revogação desta.

Ressalta-se, todavia, que os acórdãos dos Tribunais de Justiça dos Estados de Minas Gerais e do Rio Grande do Sul foram analisados na íntegra, não sendo possível esse tipo de verificação no Tribunal de Justiça do Estado do Rio de Janeiro, pois o acesso ao inteiro teor dos acórdãos na página eletrônica desse tribunal é vedado.

Partindo-se do princípio de que metodologia se refere ao “... caminho do pensamento e a prática exercida na abordagem da realidade” (Minayo, 1998, p. 16), considera-se que a presente formulação metodológica constitui uma das muitas maneiras existentes de apreensão dos dados. Não se pretendeu, portanto, descobrir verdades imutáveis por meio dessa pesquisa, mas sim ampliar a reflexão sobre as questões debatidas naquelas instâncias, especialmente por se perceber que vasta argumentação sobre o tema está apoiada em conhecimentos que parecem atribuídos às ciências humanas. 


\section{Resultados}

Com base nos acórdãos analisados foi possível categorizar os achados da pesquisa em: argumentações que dão suporte às decisões favoráveis à guarda compartilhada e argumentações que sustentam a contraindicação da guarda compartilhada.

\section{I Argumentações QUE DÃo SUPORTE Às DECISÕES FavorÁveIS À GUARDA COMPARTILHADA}

Apesar de a pesquisa realizada não ser de cunho quantitativo, mas qualitativo, chamou atenção a discrepância quanto ao número de decisões favoráveis à guarda compartilhada emitidas pelos tribunais estudados. Ou seja, enquanto no Tribunal de Justiça do Estado do Rio de Janeiro aproximadamente 25\% da jurisprudência levantada era favorável à guarda compartilhada, no Tribunal de Justiça do Estado do Rio Grande do Sul não houve registro de acórdão que decidisse favoravelmente à aplicação dessa modalidade de guarda dentre os julgados registrados. Já dos 38 acórdãos estudados do Tribunal de Justiça de Minas Gerais, apenas quatro foram favoráveis à determinação de guarda compartilhada. Considera-se, portanto, que esses números podem sugerir a inexistência de consenso no que diz respeito à aceitação desse instituto.

Em decisões favoráveis à guarda compartilhada, foram encontradas argumentações como as expostas a seguir:

A rotina da guarda compartilhada - embora possa demandar uma maior organização por parte dos genitores e da própria criança - é a que melhor atende aos interesses da menor. [...] Se não foi possível uma vida em comum entre os genitores, certo é que a criança não pode ser privada do convívio de ambos. (Proc. $\mathrm{n}^{\circ}$ 0056122-21.2006.8.19.001 (2009.001.49783) - TJRJ).

Em outro acórdão, foi ressaltado que a guarda compartilhada "é a resposta mais eficaz à continuidade das relações da criança com seus dois pais na família dissociada" (Proc. n ${ }^{\circ}$ 0171152-70.2007.8.19.0001 - TJRJ).

Nesse sentido, cabe recordar que diversos autores (Poussin e Lamy, 2005; Théry, 1998) consideram que a guarda compartilhada pode representar uma medida facilitadora para o convívio familiar, assegurando vínculos mais estáveis da criança com ambos os pais, além de favorecer a igualdade de deveres e direitos dos genitores. Simboliza, portanto, uma ancoragem social para o exercício dos papéis parentais, afastando a ideia de um genitor principal, o guardião, e um secundário ou de final de semana. Compreende-se, portanto, que as dificuldades que possam surgir nos arranjos de guarda não devem ser interpretadas apenas como questões provenientes do âmbito doméstico. Deve haver preocupação do Estado em assegurar legislações e políticas públicas que evitem o afastamento entre genitores e seus filhos, construindo-se estratégias adequadas às necessidades de cada momento histórico. 


\subsection{ArgumentaÇões Que SUSTENTAM a CONTRAindicaÇÃo da GUARda COMPARTILHAdA}

Na busca pela jurisprudência notou-se que, se por um lado a regulamentação legislativa da guarda compartilhada ampliou o alcance desse escopo jurídico, por outro parece ter provocado reações mais incisivas no que tange à não aceitação dessa modalidade de guarda por parte de alguns juristas, como demonstrado no trecho do acórdão a seguir: "Guarda compartilhada que se revela, desde sempre, como ineficaz e causadora de quantidade de problemas, especialmente em relação a crianças em fase de formação de sua personalidade" (Proc. n 2008.001.66120 - TJRJ).

Contrariamente à afirmação anterior, alguns estudiosos que desenvolveram pesquisas sobre o tema (Wallerstein e Kelly, 1998; Brito, 2008) perceberam que a guarda unilateral pode contribuir para o afastamento da criança do genitor que não permanece com a guarda, acarretando prejuízos ao desenvolvimento emocional infanto-juvenil. Singer (2008, p. 438) informa que, na Suécia, desde 1976 é possível que pais não conviventes optem pela guarda compartilhada de seus filhos. Pesquisa empreendida naquele país após essa data apontou que, quando os pais compartilhavam a guarda, os filhos mantinham melhor contato com o genitor com quem não residiam. Em 1998, a legislação daquele país estabeleceu que os tribunais podiam determinar a guarda compartilhada mesmo quando um dos pais discordava da medida. Todavia, a guarda compartilhada não pode ser imposta se ambos os pais não a desejam.

Retornando à pesquisa jurisprudencial que se empreendeu, observou-se também o direcionamento de crítica à própria redação da Lei $n^{\circ} 11.698 / 08$, por dispor sobre a aplicação dessa modalidade de guarda mesmo quando os genitores não conseguem chegar a um acordo a respeito da maneira como deve ser exercida a guarda de seus filhos:

Neste tempo, faz-se irrelevante a previsão da Lei 11698/08, que alterou o artigo 1584 do CC/02, para dele constar, em seu artigo $2^{\circ}$, que "quando não houver acordo entre a mãe e o pai quanto à guarda do filho, será aplicada, sempre que possível, a guarda compartilhada”, porquanto nem mesmo a determinação judicial no sentido de impor a guarda compartilhada às partes possibilita, no plano fático, o funcionamento desta espécie de guarda, atrelada inegavelmente à colaboração de ambos os genitores no desenvolvimento do infante (Proc. $\mathrm{n}^{\circ}$ 1.0525.08.1460806/001(1)-TJMG).

Na íntegra do acórdão supracitado, o relator afirma que essa lei significa um retrocesso no direito de família, pois entende que o critério de melhores condições, que norteia as decisões sobre a guarda unilateral, atenderia de forma mais adequada aos interesses da criança.

Brito (2002) esclarece, contudo, que esse critério já foi usado em diversos países nos anos 1970 e 1980, em substituição à noção de falta conjugal. No entanto, pesquisas 
mostraram que a busca pelo genitor com melhores condições não alterou o elevado percentual de guarda atribuído às mães, na medida em que comportamentos vistos como maternos funcionavam como elementos norteadores na apuração daquele pai que apresentasse essas características. Além desse fato, foi observado que o citado critério facilitava o acirramento do litígio entre os pais da criança, quando verdadeiras batalhas eram travadas nos tribunais, com encenações de competências de cada um dos genitores e depreciações dos mais diversos comportamentos do outro. Percebeu-se, portanto, que com esse critério a legislação contribuía, de forma inequívoca, para enfretamentos entre os genitores, além de equiparar a separação conjugal à parental: ocorrendo a primeira, a segunda era vista como inevitável. Os prejuízos emocionais que poderiam advir dessa disputa eram vistos como secundários, em razão da premência da escolha.

De forma semelhante, avaliar com quem a criança possui vínculos afetivos mais consistentes, com a finalidade de se aplicar a guarda única, pode significar condenála a uma filiação unilateral, contribuindo para que se cristalize o desconhecimento e a distância física e emocional em relação ao outro genitor.

Nos acórdãos estudados, seria possível supor, portanto, que utilizar o critério indicado para o estabelecimento da guarda unilateral pode significar uma compreensão diversa do espírito da lei sobre a guarda compartilhada. Em mero exemplo, em 10 de dezembro de 2008, foi publicada a seguinte jurisprudência:

Vê-se, pois, que na hipótese em comento, tanto a Apelante quanto o Apelado têm direito à guarda do menor. [...] Deverá, o juiz, apurar qual dos pais tem as melhores condições para exercer a guarda, sob o ponto de vista moral, educacional e afetivo, considerando a afinidade existente entre eles e os filhos (Proc. $n^{\circ}$ 1.0396.03.012019-2/001(1) - TJMG).

$\mathrm{Na}$ pesquisa foram observadas, ainda, situações consideradas inapropriadas para se aplicar a guarda compartilhada. Os sete tópicos subsequentes apresentam os argumentos mais encontrados nessa categoria.

\subsection{OCORRÊNCIA De Litígio ENTRE O EX-CASAL}

No universo de 94 acórdãos que foram cuidadosamente analisados para a presente pesquisa, 42 recursos tiveram o pedido de guarda compartilhada negado por causa da relação litigiosa entre o ex-casal, sendo possível observar que a beligerância entre os pais foi, sem dúvida, o principal motivo de impedimento para a aplicação da guarda compartilhada. Argumentações como "Guarda compartilhada é acordo. Não havendo acordo, não há guarda compartilhada” (Proc. n 70029084092 - TJRS) ou, ainda, "Ressalte-se que tal modalidade de guarda somente obtém sucesso entre casais que convivem em plena harmonia e cordialidade" (Proc. $n^{\circ}$ 1.0358.07.014534-9/001(1) TJMG) foram utilizadas repetidas vezes nos diferentes julgados. 
Em dissonância com esses argumentos, como já exposto, autores reconhecem que a avaliação do genitor que reúne melhores condições para deter a guarda única pode acirrar o litígio. Além disso, a exigência de bom relacionamento entre os pais reuniria, mais uma vez, questões conjugais e parentais. Contrariamente, o desafio hoje se situa na importância de se perceber que o processo judicial de regulamentação de guarda, por exemplo, abrange um pai e uma mãe e não um casal. Como destaca Théry (1998), se a conjugalidade de um casal foi desfeita, o que persiste e deve ser objeto de atenção é a relação do filho com cada um dos pais. Dessa maneira, conjugalidade e parentalidade devem ser tratadas por critérios distintos.

Pereira (2005) entende que seria uma injustiça privar os filhos da convivência com seus pais, tendo em vista que o divórcio é uma situação entre os genitores, e não entre estes e os filhos. O autor acrescenta, ainda, que o litígio não deve ser justificativa para a convivência familiar de crianças e adolescentes deixar de ser garantida. Nesse sentido, Silva (2005, p. 21) também compreende que "mesmo em litígio, a guarda compartilhada - em termos psicológicos, é a melhor solução para os filhos”. Evidencia-se, portanto, que na determinação de guarda o foco a ser mantido é o do direito constitucional de crianças e de adolescentes à convivência familiar, entendido não restritivamente, mas como o direito de se educado por pai e por mãe e de ter seu desenvolvimento acompanhado pelas duas linhagens.

Compreende-se, ainda, que a visão de que o novo instituto pressupõe acordo e harmonia entre o ex-casal pode trazer benefícios àquele pai visto como beligerante. Este, por não desejar compartilhar a guarda de seus filhos, poderia comunicar que não possui qualquer relacionamento, ou contato, com seu ex-cônjuge, visando a manter a guarda unilateral.

Aguilar (2006), Caldwell (2008) e Zambrano (2008) relatam que em seus países, ou seja, na Espanha, na Nova Zelândia e na Itália, respectivamente, juízes também consideram, com frequência, que o bom entendimento entre os pais seria condição essencial à aplicação da guarda compartilhada, situação que vem se alterando devido às novas legislações e aos resultados de pesquisas desenvolvidas pelas ciências humanas.

\subsubsection{INEXISTÊNCIA DE MOTIVO E/OU CONDUTA DESABONADORA DO GUARDIÃO}

De acordo com a jurisprudência estudada, em alguns casos se negou o pedido de alteração da guarda devido à inexistência de fato novo que justificasse o pedido. "Ausência de motivos que autorizem a alteração de guarda” (Proc. n. ${ }^{\circ} 70025650862$-TJRS).

Não se deve olvidar, porém, que tais solicitações não implicavam a inversão de guarda, mas a alteração de guarda - de unilateral para compartilhada -, situação que requer outros parâmetros de análise. Poder-se-ia pensar, também, que a vontade dos pais, ou de um deles (aquele que convive mais com os filhos), aliada à preocupação de se garantir o direito da criança à convivência familiar, constituiriam motivos para 
a alteração de guarda. Em pesquisa que realizou com filhos de pais separados, Brito (2008) notou que, quando questionados sobre o que gostariam de mudar na história da separação de seus pais, alguns jovens entrevistados indicavam a distância em relação ao genitor que não permaneceu com a guarda. Esse dado também foi observado em outras pesquisas, nas quais se percebeu que a vontade dos filhos é, em geral, de que as visitas esparsas não contribuam para esmaecer o contato com aquele que não detém a guarda. Como afirma Théry (1998), não se deve desprezar o papel do Estado como fiador da autoridade parental, pois esta não é de natureza exclusivamente privada, e sim função de ordem pública.

Argumentação referente à prerrogativa de "inexistência de conduta desabonadora do guardião" também foi utilizada em alguns acórdãos, nos quais os julgadores não encontraram motivos para alteração da modalidade de guarda. No presente estudo, se observou grande recorrência de justificativas para a manutenção da guarda unilateral, como a exposta a seguir: "Ademais, inexiste nos autos qualquer indicação de conduta desabonadora da genitora que pudesse afastar o exercício da guarda da filha [...]" (Proc. no 1.0079.09.923860-6/001(1) - TJMG).

Mesmo ao reconhecer que tanto o pai quanto a mãe estariam aptos para o exercício da guarda da criança, o relator da jurisprudência $n^{\circ} 70033272063$ (TJRS) optou por não aplicar a guarda compartilhada, tendo em vista que não havia fato desabonador da conduta materna no exercício da guarda única.

Brito (2005), ao entrevistar operadores do direito, aponta que estes admitiam a preferência pela guarda materna caso ambos os pais reunissem condições para o cuidado dos filhos. Atualmente, como a maioria das guardas continua sendo atribuída às mães (INSTITUTO BRASILEIRO DE GEOGRAFIA E ESTATÍSTICA, 2010), poder-se-ia supor que a ideia do já combatido mito do amor materno ainda prevalece (Badinter, 1985). Quanto a essa justificativa, Aguilar (2006, p. 89) tem percebido que também na Espanha "muchas de las argumentaciones que hoy en día se ofrecen para oponerse a la custodia compartida reflejan más posiciones ideológicas que argumentos científicos”. Espelham, assim, tradições difíceis de serem alteradas.

\subsubsection{Mudança de rotina da CRiança}

$\mathrm{Na}$ investigação levada a termo observou-se, ainda, que as Turmas Recursais muitas vezes decidiam manter a guarda unilateral por entenderem que a mudança de rotina seria prejudicial para a criança. Como exemplo, a seguinte decisão afirma: "cumpre salientar que as alterações de guarda, por significarem uma mudança significativa na vida dos menores, devem ser evitadas tanto quanto possível" (Proc. nº 70030030399 - TJRS). Outro exemplo é exposto a seguir:

Com efeito, a alteração da guarda só deve ocorrer em hipóteses excepcionais e sempre há de se ter atenção para com os eventuais traumas psicológicos, 
afetivos e sociais provenientes de alterações súbitas, sem contar no difícil processo de adaptação ao novo ambiente a que a criança estará submetida (Proc. $n^{\circ}$ 1.0024.06.026662-4/001(1) - TJMG).

De acordo com os julgados examinados, se observa que a referência feita à modificação de rotina inclui as mudanças de horários das atividades com que as crianças estariam acostumadas, como também o contato mais estreito com outro tipo de educação, que não o de seu guardião. Nesse sentido, se pode recordar que, na contemporaneidade, crianças passam grande parte do tempo longe de casa e do genitor que detém a guarda, permanecendo sob os cuidados de creches, de babás ou dos avós. No entanto, se percebe que sabem diferenciar, sem grandes conflitos, as regras de cada local de convivência.

Nota-se, entretanto, que as crianças conseguem discriminar as diferenças de procedimentos educativos empreendidos por pais, mães e avós, tanto que, muitas vezes, sabem exatamente o que solicitar a cada um, mesmo quando os pais convivem maritalmente (Brito, 2005, p. 63).

Se as crianças transitam por esses locais de convivência sem grandes preocupações ou supostos danos emocionais que essa alternância poderia lhes causar, não deveria ser difícil aceitar que, quando os pais se separam, o filho pode ter duas casas e isso não provocará, necessariamente, traumas psicológicos nesses infantes. Entende-se, hoje, que a referência a ser mantida pela criança é a de sua família, independentemente da composição que exiba.

Uma justificativa para a não aplicação da guarda compartilhada pelo Tribunal de Justiça do Estado do Rio Grande do Sul aponta:

Primeiramente, observo que as alterações de guarda devem ser evitadas tanto quanto possível, pois, em regra, são prejudiciais à criança, que tem modificada a sua rotina de vida e os seus referenciais, gerando-lhe transtornos de ordem emocional (Proc. n 70029132602 - TJRS).

Por outro lado, dados de pesquisas com filhos de pais não conviventes (Souza, 2000; Wallerstein e Kelly, 1998), apontam que a fixação de visitas, além de contribuir para fragilizar a relação de afeto entre pais e filhos, ocasiona uma evidente mudança na rotina das crianças, acostumadas ao convívio diário com ambos os pais.

Assim, Brito e Gonsalves (2009, p. 78) questionam: “o que seria fator de proteção à saúde mental da criança [...] a rotina de encontrar um dos pais esporadicamente, [...] ou a rotina do convívio em duas casas?”. 


\subsubsection{Moradias distantes}

O entendimento exposto em grande parte da jurisprudência encontrada foi o de que a guarda compartilhada não deve ser aplicada quando os genitores residem em localidades distintas, como aponta a seguinte argumentação: "Não há falar em guarda compartilhada quando os genitores residem em cidades diversas [...]" (Proc. $\mathrm{n}^{\mathrm{o}} 70022656870$ - TJRS).

A literatura sobre o tema aponta, todavia, que a noção de guarda compartilhada vai além da preocupação com dias, horários e formas de deslocamento das crianças e dos pais, como alertam Brito e Gonsalves (2009):

Ao se determinar a guarda compartilhada, indica-se aos pais a importância que o Estado atribui à convivência familiar da criança. Com esse entendimento, pode-se ultrapassar a dúvida sobre os arranjos concretos de guarda para se valorizar o aspecto simbólico da guarda compartilhada, que permite deixar de lado a interpretação de que haveria um pai principal e um secundário (Brito e Gonsalves, 2009, p. 80).

O relator de um acórdão, no Rio Grande do Sul, apesar de não deferir a guarda compartilhada por entender que esta não deveria ser imposta aos pais, aponta que: "Embora as partes não residam na mesma cidade, o ideal no caso dos autos seria a guarda compartilhada” (Proc. n ${ }^{\circ} 70033272063$-TJRS). Assim, acredita-se que, nesse caso, essa variável não seria impeditiva para a aplicação da guarda compartilhada.

Em pesquisa empreendida com pais e mães separados, Brito (2001) relata o caso de uma brasileira que se divorciou na França, onde também moravam o ex-marido e o filho em comum. No processo de divórcio, no país em questão, foi designada a autoridade parental conjunta, modalidade correlata à guarda compartilhada no Brasil, fato que não constituiu impedimento para que a entrevistada voltasse para seu país de origem com a criança, após a separação. O exercício da autoridade parental conjunta entre pai, residente na França, e mãe, residente no Brasil, ocorria por meio do contato a distância. Além de aceitar opiniões do ex-marido quanto à educação do filho, ela, ainda, "Envia sempre boletins escolares, trabalhos e desenhos, preocupada com a preservação dos laços do filho com o pai” (Brito, 2001, p. 24).

A guarda compartilhada, muito além de uma divisão estrita de dias e horários que os filhos passam com os pais, consiste na responsabilização de ambos os genitores quanto à educação e ao cuidado de seus filhos, funcionando como um suporte social simbólico que fornece sustentação à dimensão privada dos papéis parentais. A colaboração de ambos os pais na educação dos filhos após uma separação conjugal também irá depender do conjunto de significações e referências inscritas no contexto social. Por derradeiro, pode-se lembrar, ainda, que a legislação brasileira não fixa 
limites da distância que poderia existir entre a residência de cada um dos pais para que possa ser aplicada a guarda compartilhada.

\subsubsection{CRiançAS DE TENRA IDAde}

A pouca idade da criança constituiu, por vezes, forte argumentação para fundamentar a jurisprudência desfavorável à guarda compartilhada. Assim, observou-se certa vinculação entre a tenra idade do filho e o não deferimento dessa modalidade de guarda. Como exemplo, apresenta-se a seguinte argumentação: "Apesar de ambas as partes terem condições de ficar com a guarda do filho de dois anos de idade, considerando a idade da criança [...] é de rigor a manutenção da guarda provisória com a mãe" (Proc. $\left.\mathrm{n}^{\mathrm{o}} 70029084092-\mathrm{TJRS}\right)$.

Consta em outro julgado que, além de os pais estarem em litígio, o fato de a criança ainda ser amamentada pela mãe colaborou para que o pedido de guarda compartilhada fosse negado (Proc. $\mathrm{n}^{\mathrm{o}} 70030031611$ - TJRS).

Brito e Gonsalves (2009) alertam para a importância do estabelecimento de vínculos estreitos entre ambos os pais e seus filhos desde a mais tenra idade, pois pesquisas apontam para o fato de que essa aproximação se torna mais difícil com o passar do tempo. Além disso, ressalta-se que a legislação tampouco fixa idade mínima da criança que poderá ficar sob o regime de guarda compartilhada.

$\mathrm{Na}$ pesquisa, já citada, com filhos adultos de pais separados, Brito (2008) relata que os entrevistados classificaram o esquema de visitação quinzenal como insuficiente para o estabelecimento de um vínculo maior entre pai e filho e, ainda, insistiam na "... necessidade de um contato mais estreito desde a tenra idade" (Brito, 2008, p. 44). A autora promove uma reflexão sobre o estabelecimento de alianças entre pais e filhos pequenos, mostrando que, com o passar dos anos, mais difícil se torna o fortalecimento de vínculos entre genitores e filhos que não convivem. Nesse sentido, um dos entrevistados, ao relatar a ausência do genitor visitante em seu processo de crescimento, diz que só poderia haver aproximação entre eles se algo tivesse mudado "lá atrás".

Wallerstein e Kelly (1998) alertam para uma questão importante, que é a diferença da noção de intervalo de tempo entre adultos e crianças. Sobre esse assunto, Silva (2005) acredita que a ausência de um dos pais, mesmo que por alguns dias, pode gerar angústia na criança - por pensar ter sido abandonada - ou, até mesmo, contribuir para que o infante se afaste emocionalmente do genitor ausente. $O$ autor explica que:

Nesse ponto, é preciso sublinhar que a percepção psicológica que tem a criança da passagem do tempo cronológico é notavelmente diferente da percepção que tem um adulto. O que para a percepção de uma criança representa um mês pode corresponder na realidade a uma semana, segundo a percepção temporal de um adulto [...] (Silva, 2005, p. 27). 
Assim, tratando-se do exercício da guarda unilateral, os 15 dias que se passam até o momento da visitação do genitor não guardião podem significar, para a criança, um lapso temporal maior do que o real. Wallerstein e Kelly (1998, p. 61) ressaltam, ainda, que: "Dois terços das crianças, especialmente as mais jovens, ansiavam pelo progenitor ausente, metade delas com uma intensidade que nos pareceu profundamente tocante”. Dessa forma, compreende-se como fundamental, no atual momento histórico, questionar a ideia de que a guarda unilateral, com visitas esparsas, seria o melhor para as crianças, especialmente as pequenas. Considera-se que é justamente nos casos de crianças de tenra idade que deve haver preocupação e cuidado para que possam vir a estabelecer e sedimentar saudáveis e estáveis vínculos afetivos com ambos os pais. Se a convivência com um dos pais não ocorre quando o filho é pequeno, pode ser mais difícil alterar essa situação quando a criança for mais velha. Como recordam Poussin e Lamy (2005, p. 65): "No tendría ningún sentido iniciar un régimen de custodia compartida años después del nacimiento del niño, si padre e hijo no han establecido previamente un vinculo estrecho".

Em contraponto à argumentação destacada nesse item, a jurisprudência $\mathrm{n}^{\circ}$ 0038311-46.2009.8.19.0000, do Tribunal de Justiça do Estado do Rio de Janeiro, julgada em 14 de outubro de 2009, relata a existência de um caso de compartilhamento da guarda de uma criança de apenas um ano e seis meses.

\subsubsection{Conflitos NO EXERCício DA GUARdA COMPARTILHADA}

Observou-se que alguns julgados se referiam a recursos sobre decisões de primeira instância que estabeleceram a guarda compartilhada entre os pais da criança.

Seguindo tendências já vistas, como a impossibilidade de guarda compartilhada entre o ex-casal em litígio ou entre pais que moram em cidades distintas, os tribunais que receberam recursos com alegações desse tipo concordaram com o pedido de alteração da guarda compartilhada para a guarda unilateral:

... aduziu a autora que, por força do acordo celebrado na separação consensual, ficou firmada a guarda compartilhada do menor. Todavia, em virtude das constantes ofensas proferidas pelo requerido, tornou-se inviável a mantença da guarda compartilhada (Proc. n 1.0153.07.065292-7/003(1) - TJMG).

A questão que aqui se discute não se refere ao surgimento de conflitos no decorrer do exercício daquele instituto, mas sim às contrariedades em relação ao compartilhamento da guarda, apesar da previsão legal de que esta deva ser aplicada mesmo em casos de lide entre os pais da criança. Constatou-se que dificilmente as cortes decidem pela troca de modalidade de guarda quando um dos genitores alega conflitos no decorrer do exercício da guarda unilateral. Contrariamente, questões apresentadas à Justiça sobre impasses no curso da guarda compartilhada tendem à modificação de guarda. 


\subsubsection{Ampliação de visitas No lugar da guarda COMpartilhada}

Dado interessante a ser estudado é o fato de que as contrariedades apresentadas para a aplicação da guarda compartilhada não impediam a determinação da visitação livre. De acordo com a jurisprudência coletada na pesquisa, situações em que a guarda compartilhada era desaconselhada, como era o caso de famílias que não entravam em acordo quanto ao cuidado da criança de pais que moravam em cidades distantes, a orientação do julgado era no sentido da manutenção da guarda unilateral, com aplicação da visitação livre.

Notou-se que alguns operadores do direito entendem que a livre visitação se assemelha à guarda compartilhada, por, teoricamente, ampliar o convívio entre pais e filhos na família pós-divórcio.

Tenho convicção de que o apelante não possui a exata noção de que a guarda compartilhada, na prática do caso concreto, não faria a menor diferença. Isto porque a visitação do pai às filhas foi definida como livre, de sorte que não haverá qualquer restrição ao contato com as infantes (Proc. nº 70022656870 - TJRS).

O Tribunal de Justiça do Rio Grande do Sul, por exemplo, que repudiou a totalidade dos recursos de guarda compartilhada analisados, foi o que mais concedeu a visitação livre. Aproximadamente 25\% dos julgados estudados mencionavam a questão da livre visitação, a maioria de forma positiva. Seria possível pensar, entretanto, que, se os pais procuram a Justiça para regulamentar a guarda de seus filhos, pode ser justamente por não estarem conseguindo praticá-la livremente. Nesses casos, concluir pela visitação livre, como uma aparente proposta de autonomia, pode contribuir para o acirramento de litígios ou para a inexistência de visitas, dadas as dificuldades que possam surgir. Como já exposto, o entendimento de que ambos os pais são responsáveis pelos filhos e devem, portanto, decidir sobre a educação das crianças e ter seus lugares assegurados é a ideia que preside a modalidade de guarda compartilhada.

Brito (2005) aponta que a visitação ampliada também não é suficiente para legitimar o exercício do poder familiar do pai que não detém a guarda, tendo em vista que as responsabilidades pela educação dos filhos são delegadas, principalmente, ao genitor guardião. Nazareth (2005) se posiciona quanto a essa questão e diz que aplicar a visitação livre não será, necessariamente, a melhor alternativa de arranjo para a criança.

No presente estudo notou-se, ainda, que a determinação da visitação livre possui duas facetas. A primeira, já discutida, se refere à ampliação do contato entre pais e filhos, e a segunda está ligada à não obrigação do contato entre pais e filhos. Quando se fala em "livre" visitação, abre-se prerrogativa para que a visita ocorra da forma que se quer, podendo, portanto, ser rejeitada por pais ou por filhos. 
A jurisprudência $n^{\circ}$ 0011677-76.2010.8.19.0000, emitida pelo Tribunal de Justiça do Estado do Rio de Janeiro, propõe a visitação livre do genitor não guardião ao seu filho adolescente, pois este não quer ser obrigado às visitas quinzenais. Assim, o relator mantém a decisão da primeira instância e diz:

No momento, a decisão da Magistrada de estabelecer a visitação livre deverá ser observada, na tentativa de superação de obstáculos que ainda existem entre o genitor e o filho. Forçar a visitação somente contribuirá para aumentar a dificuldade de relacionamento, mormente nesta fase, de início de adolescência.

Pode-se pensar, contudo, que caberia ao poder judiciário assegurar o lugar dos pais no exercício de suas responsabilidades educativas, não deixando a situação como uma escolha a ser feita pelos filhos. Pesquisas sobre o tema (Wallerstein e Kelly, 1998; Gonzalez et al., 1994) apontam que diversos podem ser os motivos para que os filhos não queiram visitar - ou estar com - um dos pais, dentre eles um forte alinhamento com a figura do guardião. Nessa situação, conceder ao filho a opção de realizar ou não a visita só contribuiria para sedimentar essa extrema aliança com aquele que possui a guarda.

\section{CONCLUSÕES}

No Brasil, a promulgação da Lei n ${ }^{\circ}$ 11.698/08 era aguardada com expectativa por muitos pais que vislumbravam um novo cenário nas determinações dos arranjos de guarda de filhos de genitores não conviventes. Com o aumento do número de separações, cresceu também o número de pesquisas sobre o tema, constatando-se a necessidade premente de, nos dias de hoje, o Estado garantir a autoridade parental de ambos os pais, na medida em que a guarda unilateral foi avaliada como modalidade que pode contribuir para o afastamento entre pais e filhos. Como apontam diversos estudos apresentados ao longo do trabalho, no contexto contemporâneo é preciso desmembrar conjugalidade e parentalidade avaliando quais as medidas judiciais que melhor se aplicam a cada uma.

Na pesquisa que se realizou com a jurisprudência publicada entre agosto de 2008 e abril de 2010 por tribunais de três estados, se identificou uma série de situações que, com frequência, são compreendidas como fatores que impedem a aplicação da guarda compartilhada. Nos acórdãos estudados, chamou atenção o elevado número de julgados nos quais se contraindicava a guarda compartilhada, dado que pode sugerir certa resistência quanto ao emprego dessa modalidade de guarda. Assim, a desarmonia entre os pais da criança, a inexistência de fato novo que justificasse a alteração de guarda, as mudanças na rotina da criança, a distância entre as moradias dos pais, o fato de o processo de guarda envolver criança de tenra idade, a existência de conflitos no 
exercício da guarda e a concessão de visitação livre foram as justificativas mais usadas para se negar a aplicação da guarda compartilhada.

A manutenção do convívio da criança com ambos os pais foi, no entanto, a principal argumentação que deu suporte às decisões favoráveis à guarda compartilhada, certamente em número menor do que os julgados contrários.

$\mathrm{Na}$ investigação empreendida, foi possível concluir pela existência de certa dissonância entre os argumentos utilizados para se negar a aplicação da guarda compartilhada e os resultados de trabalhos e pesquisas desenvolvidos pelas ciências humanas sobre o tema. Ou seja, os achados das pesquisas não fornecem dados que sustentem as conclusões dos referidos julgados. Tampouco se encontram na Lei $n^{0} 11.698 / 08$ as justificativas alegadas em muitos acórdãos. Sugere-se, portanto, que haja mais interlocução entre as diversas áreas de conhecimento, inclusive por meio de debates e discussões sobre o tema da guarda compartilhada.

Retornando ao entendimento de Minayo (1998) acerca dos cuidados a serem observados no decorrer de pesquisas, pode-se recordar que o estudo de questões sociais caracteriza-se por seu dinamismo e pela provisoriedade de seus achados. Não se pretende, portanto, encerrar aqui a discussão sobre a aplicação da guarda compartilhada, ao contrário, buscou-se com este trabalho alcançar indícios da argumentação evocada em acórdãos logo após a promulgação da lei que regula a guarda compartilhada no Brasil. Acredita-se, ainda, que a presente investigação pode contribuir ou embasar novos trabalhos e discussões teóricas que colaborem para se garantir, de forma saudável, a convivência familiar de crianças e de adolescentes.

: ARTIGO APROVADO (15/05/2013) : RECEBIDO EM 23/01/2011

\section{REFERÊNCIAS BIBLIOGRÁFICAS}

AGUILAR, José Manuel. Com mamá y com papá. España: Almuzara, 2006.

BADINTER, Elisabeth. Um amor conquistado: o mito do amor materno. Rio de Janeiro: Nova Fronteira, 1985. BRASIL. Código Civil. Lei no 10.406, de 10 de janeiro de 2002. Disponível em: <http://www.planalto.gov.br/ ccivil_03/LEIS/2002/L10406.htm>. Acesso em: 23 mai. 2010.

. Lei $\mathrm{n}^{\circ}$ 11.698/08, de 13 de junho de 2008. Disponível em: <http://www.planalto.gov.br/ccivil_03/ _Ato2007-2010/2008/Lei/L11698.htm>. Acesso em 23 mai. 2010.

Projeto de Lei $n^{\circ}$ 6.350/2002. Define a guarda compartilhada. Disponível em: <http://www.mp.rs.gov.br/ infancia/legislacao/id2656.htm>. Acesso em: 15 jun. 2010.

BRITO, Leila Maria T. Descumprimento de visitação e a questão penal. Revista Brasileira de Direito de Família, Porto Alegre, n. 8, p. 18-29, jan./mar. 2001. 
Impasses na condição da guarda e da visitação: o palco da discórdia. In: CONGRESSO BRASILEIRO DE DIREITO DE FAMÍlia, 3., 2002, Belo Horizonte. Anais... Belo Horizonte: Del Rey/IBDFAM, 2002. p.433-448.

Guarda compartilhada: um passaporte para a convivência familar. In: APASE (Org.). Guarda compartilhada: aspectos psicológicos e jurídicos. Porto Alegre: Equilíbrio, 2005. p. 53-71.

Alianças desfeitas, ninhos refeitos: mudanças na família pós-divórcio. In: (Org.). Famílias e separações: perspectivas da psicologia jurídica. Rio de Janeiro: EdUERJ, 2008. p. 17-48.

BRITO, Leila Maria T.; GONSALVES, Emmanuela N. Razões e contra-razões para aplicação da guarda compartilhada. Revista dos Tribunais, São Paulo, v. 886, ano 98, p. 69-86, ago. 2009.

CALDWELL, John. Children: new developments. In: ATKIN, Bill (Ed.). The international survey of family law. Bristol: Jordan, 2008. p. 275-292.

CARVALHO, Paulo de Barros. O preâmbulo e a prescritividade constitutiva dos textos jurídicos. Revista Direito GV, São Paulo, v. 6, n.1, p. 295-312, jan./jun. 2010.

GOMES, Romeu. A análise de dados em pesquisa qualitativa. In: MINAYO, M. C. S. (Org.). Pesquisa social: teoria, método e criatividade. Petrópolis: Vozes, 1998. p. 67-80.

GONZALEZ, Martha R. et al. Percepciones parentales en niños de familias separadas: una nueva versión del Sindrome de Estocolmo? Anuário de Psicologia Jurídica, Madrid, p. 25-43, 1994.

HURSTEL, Françoise. As novas fronteiras da paternidade. Campinas: Papirus, 1999.

INSTITUTO BRASILEIRO DE GEOGRAFIA E ESTATÍSTICA. Estatística do registro civil de 2008. Disponível em:

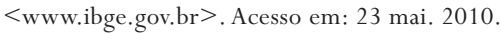

MINAS GERAIS. Tribunal de Justiça do Estado de Minas Gerais. Câmaras Cíveis Isoladas / $3^{\text {a }}$ CÂMARA CÍVEL. FAMÍLIA - APELAÇÃO - AÇÃO DE ALTERAÇÃO DE GUARDA - CERCEAMENTO DE DEFESA INOCORRÊNCIA - GUARDA COMPARTILHADA - AUSÊNCIA DE ACORDO ENTRE OS PAIS INVIABILIDADE - PERMANÊNCIA ALTERNADA DO MENOR COM SEUS GENITORES - GUARDA ALTERNADA - IMPOSSIBILIDADE. Apelação Cível: 1.0525.08.146080-6/001. Relator: Dídimo Inocêncio de Paula. Data de Julgamento: 25/02/2010. Data da publicação da súmula: 16/03/2010. Disponível em: $<$ http://www5.tjmg.jus.br/jurisprudencia/pesquisaNumeroCNJEspelhoAcordao.do?numeroRegistro $=1 \&$ tot alLinhas $=1 \&$ linhasPorPagina $=10 \&$ numeroUnico $=1.0525 .08 .146080-6 \% 2 \mathrm{~F} 001 \&$ pesquisaNumeroCNJ $=$ Pesquisar>. Acesso em: 23 abr. 2010.

MINAS GERAIS. Tribunal de Justiça do Estado de Minas Gerais. Câmaras Cíveis Isoladas / $4^{\text {a }}$ CÂMARA CÍVEL. DIREITO DE FAMÍLIA - GUARDA DE MENOR - IMPOSSIBILIDADE DE GUARDA CONJUNTA - PAI DETENTOR DA GUARDA DE FATO - CRITÉRIOS PARA DETERMINAÇÃO DA GUARDA - PRINCÍPIO DO MELHOR INTERESSE DO MENOR. Apelação Cível: 1.0396.03.012019-2/001. Relator: Dárcio Lopardi Mendes. Data de Julgamento: 27/11/2008. Data da publicação da súmula: 10/12/2008. Disponível em: <http://www5.tjmg.jus.br/jurisprudencia/pesquisaNumeroCNJEspelhoAcordao.do?numeroRegistro=1\&totalL inhas $=1 \&$ linhasPorPagina $=10$ \& numeroUnico $=1.0396 .03 .012019-2 \% 2 \mathrm{~F} 001 \&$ pesquisa NumeroCNJ $=$ Pesquisar $>$. Acesso em: 23 abr. 2010.

MINAS GERAIS. Tribunal de Justiça do Estado de Minas Gerais. Câmaras Cíveis Isoladas / $3^{\text {a }}$ CÂMARA CÍvEL. APELAÇÃO CÍVEL. AÇÃO DE DIVÓRCIO CONSENSUAL. ALIMENTOS PARA OS FILHOS. GUARDA COMPARTILHADA. REDUÇÃO. . Apelação Cível: 1.0358.07.014534-9/001. Relator: Albergaria Costa. Data de Julgamento: 20/08/2009. Data da publicação da súmula: 02/10/2009. Disponível em: <http://www5.tjmg.jus.br/ jurisprudencia/pesquisaNumeroCNJEspelhoAcordao.do?numeroRegistro=1\&totalLinhas =1\&linhasPorPagina =10\&nu meroUnico=1.0358.07.014534-9\%2F001\&pesquisaNumeroCNJ=Pesquisar >. Acesso em: 23 abr. 2010. MINAS GERAIS. Tribunal de Justiça do Estado de Minas Gerais. Câmaras Cíveis Isoladas / $3^{\text {a }}$ CÂMARA CÍVEL. AGRAVO DE INSTRUMENTO - AÇÃO CAUTELAR DE SEPARAÇÃO DE CORPOS C/C GUARDA - GUARDA PROVISÓRIA - PREPONDERÂNCIA DO DIREITO/INTERESSE DO MENOR. Apelação Cível: 1.0079.09.923860-6/001. Relator: Elias Camilo. Data de Julgamento: 22/10/2009. Data da publicação da súmula: 06/11/2009. Disponível em: <http://www5.tjmg.jus.br/jurisprudencia/ pesquisaNumeroCNJEspelhoAcordao. do?numeroRegistro $=1$ \& totalLinhas $=1$ \&linhasPorPagina $=10$ \&numeroUn ico $=1.0079 .09 .923860-6 \% 2 F 001 \&$ pesquisaNumeroCNJ=Pesquisar $>$. Acesso em: 23 abr. 2010. MINAS GERAIS. Tribunal de Justiça do Estado de Minas Gerais. Câmaras Cíveis Isoladas / $8^{a}$ CÂMARA CÍVEL. AÇÃO DE REGULAMENTAÇÃO DE GUARDA - MENOR QUE RESIDE COM O PAI PREVALECIMENTO DO INTERESSE DO INFANTE - CONFIRMAÇÃO DA SENTENÇA. Apelação Cível: 1.0024.06.026662-4/001. Relator: Silas Vieira. Data de Julgamento: 14/08/2008. Data da publicação da súmula: 03/09/2008. Disponível em: <http://www5.tjmg.jus.br/jurisprudencia/

pesquisaNumeroCNJEspelhoAcordao.do?numeroRegistro=1\&totalLinhas $=1$ \&linhasPorPagina $=10$ \&numeroUn ico $=1.0024 .06 .026662-4 \% 2 \mathrm{~F} 001 \&$ pesquisaNumeroCNJ=Pesquisar $>$. Acesso em: 23 abr. 2010. 
MINAS GERAIS. Tribunal de Justiça do Estado de Minas Gerais. Câmaras Cíveis Isoladas / 5 a CÂMARA CÍVEL. DIREITO DE FAMÍLIA E PROCESSUAL CIVIL. GUARDA. PREVALÊNCIA DO INTERESSE DA CRIANÇA. CERCEAMENTO DE DEFESA. INOCORRÊNCIA. Apelação Cível: 1.0153.07.065292-7/003. Relator: Maria Elza. Data de Julgamento: 23/04/2009. Data da publicação da súmula: 13/05/2009. Disponível em:

<http://www5.tjmg.jus.br/jurisprudencia/pesquisaNumeroCNJEspelhoAcordao.do?numeroRegistro=1\&totalL inhas $=1 \&$ linhasPorPagina $=10 \&$ numeroUnico $=1.0153 .07 .065292-7 \% 2 F 003 \&$ pesquisaNumeroCNJ $=$ Pesquisar $>$. Acesso em: 23 abr. 2010.

MINAYO, Maria Cecília de Souza. Ciência, técnica e arte: o desafio da pesquisa social. In: MINAYO, M. C. S. M. (Org.). Pesquisa social: teoria, método e criatividade. Petrópolis: Vozes, 1998. p. 9-30.

NAZARETH, Eliana Riberti. Guarda compartilhada e mediação familiar: a importância da convivência. In: APASE (Org.). Guarda compartilhada: aspectos psicológicos e jurídicos. Porto Alegre: Equilíbrio, 2005. p. 89-96.

PELAJO, Samantha. Entrevista: A guarda compartilhada é uma tendência mundial. Tribuna do Advogado, Rio de Janeiro, n. 469, ano 35, p. 28, jul. 2008.

PEREIRA, Rodrigo da Cunha. Apresentação. In: APASE (Org.). Guarda compartilhada: aspectos psicológicos e jurídicos. Porto Alegre: Equilíbrio, 2005. p. 7-8.

POUSSIN, Gerard; LAMY, Anne. Custodia compartida. Espanha: Espasa, 2005.

RIO DE JANEIRO. Tribunal de Justiça do Estado do Rio de Janeiro. $15^{\text {a }}$ Câmara Cível. Guarda e responsabilidade. Ação proposta por genitor de menor pretendendo a guarda da filha. Sentença que acolhe parcialmente o pedido para conceder a guarda compartilhada da filha comum, restando a guarda física com o genitor. Apelo afirmando concordar a mãe com a guarda compartilhada, pretendendo apenas a reforma parcial da sentença no que diz respeito aos horários dos finais de semana alternados em que lhe foi concedida a possibilidade de conviver com a filha. Apelação Cível: 0056122-21.2006.8.19.0001. Relator: GALDINO SIQUEIRA NETTO. Data de Julgamento: 23/02/2010. Ementário: 06/2010 - N. 8 - 02/06/2010. Disponível em: <http://www.tjrj.jus.br/ scripts/weblink.mgw $>$. Acesso em: 25 abr. 2010.

RIO DE JANEIRO. Tribunal de Justiça do Estado do Rio de Janeiro. $5^{\text {a }}$ Câmara Cível. GUARDA.

MODIFICAÇÃO DE CLÁUSULA POSTULADA PELO GENITOR, PRETENDENDO A GUARDA EXCLUSIVA DO FILHO. SENTENÇA DE PARCIAL PROCEDÊNCIA CONCEDENDO A GUARDA COMPARTILHADA.. Apelação Cível: 0171152-70.2007.8.19.0001. Relator: ANTONIO SALDANHA PALHEIRO. Data de Julgamento: 23/02/2010. Disponível em: <http://www.tjrj.jus.br/scripts/weblink.mgw?MGWLPN= DIGITAL1A\&PGM =WEBJRP104xHOM $\&$ PORTAL $=1 \&$ Consulta $=$ NUMERO $\&$ ROTINA $=$ WEBJRP104xHOM $\&$ L $\mathrm{AB}=\mathrm{XJRP} \times \mathrm{WEB} \& \mathrm{~N}=200900173555 \& \mathrm{ORIGEM}=1 \& \mathrm{ANOTIPO}=200901 \& \mathrm{NUMERO}=73555 \& \mathrm{EME}=1 \& \mathrm{PROCF}$ $\mathrm{OR}=2009.001 .73555 \& \mathrm{CNJ}=0171152-70.2007 .8 .19 .0001>$. Acesso em: 25 abr. 2010.

RIO DE JANEIRO. Tribunal de Justiça do Estado do Rio de Janeiro. $18^{\mathrm{a}}$ Câmara Cível. Família. Posse e guarda de menor. Sentença que defere a mesma ao genitor. Apelação.. Apelação Cível: 0007620-58.2005.8.19.0204. Relator: PEDRO FREIRE RAGUENET. Data de Julgamento: 03/03/2009. Ementário: 17/2009 - N. 11 07/05/2009. Disponível em: <http://www.tjrj.jus.br/scripts/weblink.mgw>. Acesso em: 25 abr. 2010. RIO GRANDE DO SUL. Tribunal de Justiça do Estado do Rio Grande do Sul. 8 a Câmara Cível. AGRAVO DE INSTRUMENTO. UNIÃO ESTÁVEL. GUARDA. GUARDA COMPARTILHADA. VISITAS.

ALIMENTOS.. Apelação Cível: 70029084092. Relator: Rui Portanova. Data de Julgamento: 18/12/2009. Publicação: Diário da Justiça do dia 08/01/2010. Disponível em: <http://www.tjrs.jus.br/busca/?q= $70029084092 \& \mathrm{tb}=$ jurisnova\&partialfields $=$ tribunal $\% 3 \mathrm{ATribunal} \% 2520 \mathrm{de} \% 2520 \mathrm{Justi} \% 25 \mathrm{C} 3 \% 25 \mathrm{~A} 7 \mathrm{a} \% 2520 \mathrm{do} \%$ 2520RS.\%28TipoDecisao\%3Aac\%25C3\%25B3rd\%25C3\%25A3o\%7CTipoDecisao\%3Amonocr\%25C3\%25A1tica \%7CTipoDecisao\%3Anull\%29\&requiredfields=\&as_q=>. Acesso em: 24 abr. 2010.

RIO GRANDE DO SUL. Tribunal de Justiça do Estado do Rio Grande do Sul. $7^{\mathrm{a}}$ Câmara Cível. APELAÇÃO CÍVEL. AÇÃO DE ALIMENTOS CUMULADA COM GUARDA E REGULAMENTAÇÃO DE VISITAS. AUSENCIA DE MOTIVOS QUE AUTORIZEM A ALTERAÇÃO DE GUARDA. INCONVENIENTE, NO CASO, O DEFERIMENTO DE GUARDA COMPARTILHADA. CABÍVEL A AMPLIAÇÃO DO DIREITO DE VISITAS, PROPICIANDO UMA RELAÇÃO DE MAIOR PROXIMIDADE ENTRE O MENOR, O PAI E A FAMÍLIA PATERNA. DESCABIMENTO DA REDUÇÃO DOS ALIMENTOS. ANÁLISE DAS NECESSIDADES E POSSIBILIDADES DAS PARTES. PROPORCIONALIDADE.. Apelação Cível: 70025650862. Relator: Ricardo Raupp Ruschel. Data de Julgamento: 28/01/2009. Publicação: Diário da Justiça do dia 09/02/2009. Disponível em: <http:/ /www.tjrs.jus.br/busca $/$ ?q $=70025650862 \&$ tb $=$ jurisnova\&partialfields $=$ tribunal\%3ATribunal\%2520de\%2520Justi\%25C3\%25A7a\%2520do\%2520RS.\%28TipoDecisao\%3Aac\%25C3\% 25B3rd\%25C3\%25A30\%7CTipoDecisao\%3Amonocr\%25C3\%25A1tica\%7CTipoDecisao\%3Anull\%29\&require dfields=\&as_q=>. Acesso em: 24 abr. 2010.

RIO GRANDE DO SUL. Tribunal de Justiça do Estado do Rio Grande do Sul. $7^{\text {a }}$ Câmara Cível. APELAÇÃO CÍVEL. AÇÃO DE SEPARAÇÃO JUDICIAL LITIGIOSA. ESTABELECIDA GUARDA COMPARTILHADA. 
FATO SUPERVENIENTE, QUE IMPOSSIBILITA SEU EXERCÍCIO. GUARDA FÁTICA QUE VEM SENDO EXERCIDA PELA GENITORA, QUE MUDOU SUA RESIDÊNCIA PARA OUTRA CIDADE, LEVANDO CONSIGO AS MENORES. MANUTENÇÃO DA GUARDA COM A GENITORA, EVITANDO-SE MAIS ALTERAÇÕES BRUSCAS NA ROTINA DAS MENINAS, RESGUARDADO O DIREITO DE VISITAS PELO GENITOR. RECURSO DESPROVIDO. Apelação Cível: 70030030399. Relator: Ricardo Raupp Ruschel. Data de Julgamento: 16/12/2009. Publicação: Diário da Justiça do dia 23/12/2009. Disponível em: $<$ http: / / www.tjrs.jus.br/busca $/$ qq $=70030030399+\&$ tb=jurisnova\&partialfields $=$ tribunal $\% 3$ ATribunal $\% 2520$ de\%2520Justi\%25C3\%25A7a\%2520do\%2520RS.\%28TipoDecisao\%3Aac\%25C3\%25B3rd\%25C3\%25A3o\%7 CTipoDecisao\%3Amonocr\%25C3\%25A1 tica\%7CTipoDecisao\%3Anull\%29\&requiredfields=\&as_q=>. Acesso em: 24 abr. 2010.

RIO GRANDE DO SUL. Tribunal de Justiça do Estado do Rio Grande do Sul. $7^{\mathrm{a}}$ Câmara Cível. ALTERAÇÃO DE GUARDA. DISPUTA ENTRE OS PAIS DA CRIANÇA. 1 Apelação Cível: 70029132602. Relator: Sérgio Fernando de Vasconcellos Chaves. Data de Julgamento: 11/11/2009. Publicação: Diário da Justiça do dia 17/11/2009. Disponível em: <http://www.tjrs.jus.br/busca/?q=70029132602\&tb=jurisnova\&partialfields= tribunal\%3ATribunal\%2520de\%2520Justi\%25C3\%25A7a\%2520do\%2520RS.\%28TipoDecisao\%3 Aac\%25C3 \%25B3rd\%25C3\%25A3o\%7CTipoDecisao\%3Amonocr\%25C3\%25A1tica\%7CTipoDecisao\%3Anull\%29\&requ iredfields=\&as_q=> . Acesso em: 24 abr. 2010.

RIO GRANDE DO SUL. Tribunal de Justiça do Estado do Rio Grande do Sul. $8^{a}$ Câmara Cível. APELAÇÃO CÍVEL. AÇÃO DE DIVÓRCIO JUDICIAL. Transcorrido o prazo legal e havendo concordância da parte adversa, nada obsta o divórcio pretendido. GUARDA DE FILHOS. Não há falar em guarda compartilhada quando os genitores residem em cidades diversas e se mostram litigantes, inviabilizando o alcance do escopo legislativo da guarda compartilhada. ALIMENTOS. Presumidas as necessidades das filhas, que se encontram em idade escolar, e considerando os sinais exteriores de riqueza do genitor, não há razão para reduzir a verba fixada em sentença como adequação ao caso concreto. PARTILHA. EMPRESA EXTINTA. A empresa, da qual a divorcianda era detentora da metade das quotas, ao tempo da separação, ainda que atualmente extinta, deverá ser considerada na partilha, assim como os seus débitos à época. REGIME DE BENS. Extingue-se o regime de comunhão universal de bens com a separação de fato, de sorte que as prestações de financiamento imobiliário adimplidas pelo varão após tal marco não se incluem na partilha. Apelação Cível: 70022656870. Relator: Alzir Felippe Schmitz. Data de Julgamento: 18/09/2008. Publicação: Diário da Justiça do dia 26/09/2008. Disponível em: <http://www.tjrs.jus.br/busca/?q=70022656870\&tb=jurisnova\&partialfields= tribunal\%3ATribunal\%2520de\%2520Justi\%25C3\%25A7a\%2520do\%2520RS.\%28TipoDecisao\%3Aac\%25C3 \%25B3rd\%25C3\%25A3o\%7CTipoDecisao\%3Amonocr\%25C3\%25A 1 tica\%7CTipoDecisao\%3Anull\%29\&requ iredfields=\&as_q=> . Acesso em: 24 abr. 2010.

RIO GRANDE DO SUL. Tribunal de Justiça do Estado do Rio Grande do Sul. $8^{a}$ Câmara Cível. AGRAVO DE INSTRUMENTO. “AÇÃO DE RECONHECIMENTO E DISSOLUÇÃO DE SOCIEDADE DE FATO COM PARTILHA DE BENS E GUARDA COMPARTILHADA DE MENOR A TÍTULO DE ADIANTAMENTO DE TUTELA”. GUARDA DE MENOR. Apelação Cível: 70033272063. Relator: Alzir Felippe Schmitz. Data de Julgamento: 17/12/2009. Publicação: Diário da Justiça do dia 12/01/2010. Disponível em: $<$ http: / / www.tjrs.jus.br/busca/?q=70033272063\&tb=jurisnova\&partialfields=tribunal\%3ATribunal\%2520d e\%2520Justi\%25C3\%25A7a\%2520do\%2520RS.\%28TipoDecisao\%3Aac\%25C3\%25B3rd\%25C3\%25A3o\%7C TipoDecisao\%3Amonocr\%25C3\%25A1 tica\%7CTipoDecisao\%3Anull\%29\&requiredfields=\&as_q=>. Acesso em: 24 abr. 2010.

RIO GRANDE DO SUL. Tribunal de Justiça do Estado do Rio Grande do Sul. $8^{\text {a }}$ Câmara Cível. AGRAVO DE INSTRUMENTO. ALIMENTOS PROVISIONAIS. GUARDA COMPARTILHADA. REGULAMENTAÇÃO DE VISITAS.. Apelação Cível: 70030031611. Relator: Rui Portanova. Data de Julgamento: 27/08/2009. Publicação: Diário da Justiça do dia 03/09/2009. Disponível em: <http://www.tjrs.jus.br/busca/ $? q=70030031611 \& \mathrm{tb}=$ jurisnova\&partialfields $=$ tribunal $\% 3 \mathrm{ATribunal} \% 2520 \mathrm{de} \% 2520 \mathrm{Justi} \% 25 \mathrm{C} 3 \% 25 \mathrm{~A} 7 \mathrm{a} \% 25$ 20do\%2520RS.\%28TipoDecisao\%3Aac\%25C3\%25B3rd\%25C3\%25A3o\%7CTipoDecisao\%3Amonocr\%25C3 \%25A1tica\%7CTipoDecisao\%3Anull\%29\&requiredfields=\&as_q=>. Acesso em: 24 abr. 2010.

SILVA, Evandro Luiz. Guarda de filhos: aspectos psicológicos: In: APASE (Org.). Guarda compartilhada: aspectos psicológicos e jurídicos. Porto Alegre: Equilíbrio, 2005. p. 13-32.

SINGER, Anna. Adjusting to reality: awareness of domestic violence calls for changes in Swedish family law. In: ATKIN, Bill (Ed.). The international survey of family law. Bristol: Jordan, 2008. p. 437-444.

SOUZA, Rosane Mantilla. Depois que papai e mamãe se separaram: um relato dos filhos. Psicologia: Teoria e Pesquisa, v. 16, n. 3, p. 203-211, 2000.

THÉRY, Irène. Couple, filiation et parenté aujourd'hui: le droit face aux mutations de la famille et de la vie privée. Paris: Odile Jacb; La Documentation Française, 1998. 
WALLERSTEIN, Judith; KELLY, Joan B. Sobrevivendo à separação: como pais e filhos lidam com o divórcio. Porto Alegre: ArtMed, 1998.

WALLERSTEIN, Judith; LEWIS, Julia; BLAKESLEE, Sandra. Filhos do divórcio. São Paulo: Loyola, 2002.

ZAMBRANO, Virginia. Allocating child shared custody to separating or divorcing couples: law 54/2006. In:

ATKIN, Bill (Ed.). The international survey of family law. Bristol: Jordan, 2008 p. 205-222.

\section{Leila Maria Torraca de Brito}

Rua São Francisco Xavier, n. 524, sala 10.001 B Maracanã - 20550-900 Rio de Janeiro - RJ - Brasil torracalauerj.br

Rua São Francisco Xavier, 246/701 Maracanã - 20550-012 Rio de Janeiro - RJ - Brasil engpsidayahoo.com.br
Professora Adjunta do Instituto de Psicologia da Universidade do Estado do RIO dE JANEIRO (UERJ)

Pós-Doutora EM DiREITO PELA Universidade Federal do Paraná

Mestre e Doutora em Psicologia pela PuC/RJ

\section{Emmanuela Neves Gonsalves}

ESPECIALISTA EM PSICOLOgIA JuRÍdICA PELA Universidade do Estado do RIO DE JANEIRO (UERJ)

Psicóloga 
